\title{
PD Dr. Diane Renz: Erfolgreiche Habilitation an der Charité Berlin
}

„Ab sofort sind Sie Privatdozentin.“ Mit diesen Worten überreichte Herr Prof. Dr. Bernd Hamm, Direktor des radiologischen
Instituts der Berliner Charité, am Montag, 16. Juni 2014 die Habilitationsurkunde an Frau PD Dr. Diane Renz, die seit vielen Jah-

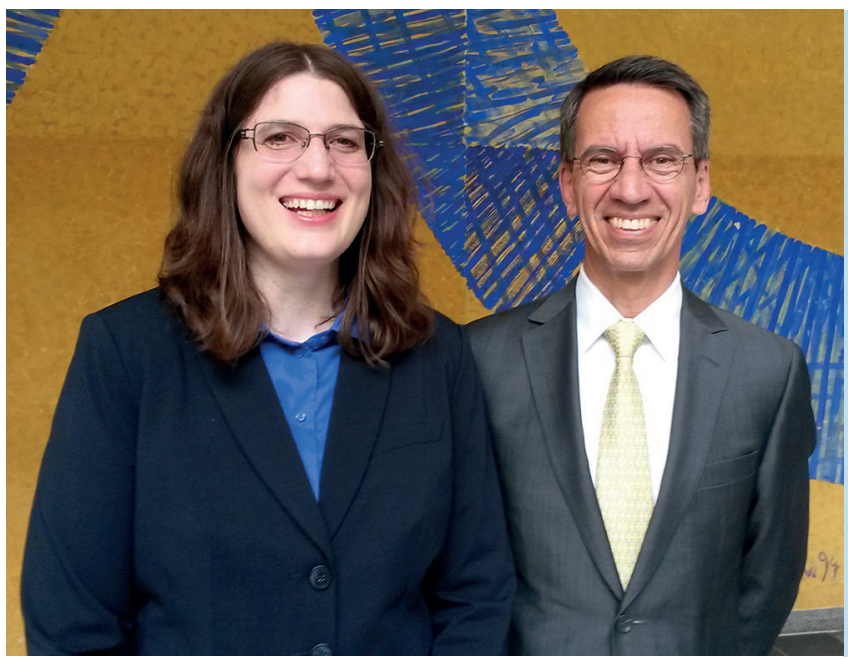

PD Dr. med. Diane Renz (links) und Prof. Dr. med. Bernd Hamm (rechts) beim Festakt der Antrittsvorlesung am Montag, 16.06.2014, an der Berliner Charité ren das Nachwuchsportal www.hellstekoepfe.de der Deutschen Röntgengesellschaft durch ihre journalistischen Beiträge bereichert. Im geschichtsträchtigen Gustav-Bucky-Hörsaal der Radiologie des Virchow-Klinikums hatte Diane Renz ihre Antrittsvorlesung zum Thema „Können computerassistierte Diagnoseverfahren in Zukunft Radiologen ersetzen?" mit Bravour gehalten. Ihre Habilitationsarbeit trägt den Titel „Computerassistierte Diagnoseverfahren in der Radiologie: Klinische Anwendungen, Benefit und Limitationen“.

Die in Sindelfingen geborene Fachärztin für Radiologie hat in Mainz, Aachen und Dijon Medizin studiert. 2013 wurde sie mit dem Gustav-Bucky-Preis der Berliner Röntgengesellschaft ausgezeichnet. Für die Mitarbeit im Team der Hellste-KöpfeRedaktion ist Diane Renz besonders geeignet, da sie zudem Absolventin der Deutschen Journalistenschule in München ist. 